\title{
Physician personality and patient confidence
}

\author{
Jonathan Kopel BS
}

\begin{abstract}
The Myers-Briggs Type Indicator (MBTI) is a reliable and valid screening test for describing the natural personality of an individual, especially in the medical field. The indicator gives an individual a four-letter abbreviation summarizing his/her personality characteristics. The categories include: extraverted (E) / introverted (I), sensing (S) / intuition (N), feeling $(F) /$ thinking $(T)$, and perception $(P) /$ judgment $(J)$. The personality types of physicians vary considerably across the medical field. Specific personality types indicated by the Myers-Briggs fit better with certain medical specialties than others. The alignment of physician-patient personalities and its effect on patient confidence and compliance have potential importance in the management of some disorders, such as, for example, substance abuse. This review will examine the alignment of physician-patient personalities and its effect on patient confidence and treatment outcomes.
\end{abstract}

Keywords: Myers-Briggs type indicator, physician personality, thinking, feeling, patient confidence

\section{INTRODUCTION}

One of the most essential aspects of medicine is embodied in the physician-patient relationship. Within this relationship, physicians acquire intimate details about their patients while respecting their autonomy. Each physician-patient relationship is enhanced by effective physician communication and the ability to gain the patient's confidence, without which it is nearly impossible to gain the patient's compliance with treatment goals. In recent years, the importance of improving physician-patient communication has been addressed in the medical literature. ${ }^{1-12}$ For example, studies on patients with breast cancer and on preoperative patients have reported improved treatment outcomes with physicians who established effective communication with their patients. ${ }^{13-15}$ Additional

Corresponding author: Jonathan Kopel

Contact Information: Jonathan.kopel@ttuhsc.edu DOI: 10.12746/swrccc.v6i26.502 studies have also demonstrated a link between physician communication skills and patient satisfaction with their interaction and treatment. ${ }^{16-19}$ A study from the University of Chicago Hospital's General Internal Medicine service surveying 300,120 patients found a positive relationship between overall satisfaction and the rating of the attending physicians' communication behaviors. ${ }^{16}$ Only thirty-three percent of physicians were rated high in all communication categories measured revealing a large communication gap between physician-patient perceptions and expectations. ${ }^{16}$ Another clinical study in the United Kingdom (UK) indicated that physician training in personality types may benefit physician-patient communication and treatment outcomes. ${ }^{20}$ Specifically, physicians and patients differed most significantly in their preferences for acquiring and processing information related to the diagnosis and management of the patients' conditions. ${ }^{20}$ With respect to the skill required in matching physician and patient personalities, "Experienced clinicians are likely to learn how to do this through trial and error over many years of medical practice and developing maturity ... medical 
students may benefit from learning these differences at an early stage of their training, so they are aware of them and can appreciate the effect of these differences during clinical encounters. This might help them develop the ability to adjust or flex their style more quickly than relying solely on experience." ${ }^{20}$ As such, understanding the effects of personality types in physician-patient communication on patient co nfidence should improve patient care and interactions. ${ }^{21,22}$

However, a basic understanding of personality influences on communication and patient outcomes is not included in most medical curricula. Despite extensive training, physicians consistently overestimate their communications skills and rely heavily on basic communication techniques learned during medical school. ${ }^{23,24}$ Improved communication skills can create and sustain a successful therapeutic doctor-patient relationship, which consists of shared perceptions and feelings regarding the nature of the problem, goals of treatment, and psychosocial support. ${ }^{25}$ Therefore, a greater focus on the alignment of physician-patient personality traits is needed in the modern medical curriculum and residency training. One method for improving communication within the medical field is through the application of the MyersBriggs Type Indicator (MBTI).

\section{MyeRs-BRIgGs TyPE InDICATOR (MBTI) AND PHYSICIAN PERSONALITY}

The MBTI is a reliable and valid method for describing the natural personality characteristics of an individual. ${ }^{26-31}$ The MBTI was originally developed by Katharine $\mathrm{C}$. Briggs to improve communication, understanding, and decisions in the workforce. ${ }^{32}$ Knowing one's personality type provides a deeper appreciation for strengths, weaknesses, and areas for potential growth in developing constructive communication and relationships. ${ }^{32}$ For example, P. Brian Cunningham discovered that using MBTI improved communication, teamwork, and the appreciation for personality differences among his doctoral students. ${ }^{33}$ In particular, Cunningham observed improvement in communication and interactions when he adjusted his communication to match his students' personality preferences. ${ }^{33}$ The MBTI gives an individual a four-letter abbreviation summarizing his/her personality type in energy, information acquisition, decision making, and orientation to the outside world. ${ }^{32}$ The categories include: extraverted $(E) /$ introverted $(\mathrm{I})$, sensing (S) / intuition $(N)$, feeling $(F) /$ thinking $(\mathrm{T})$, and perception $(\mathrm{P}) /$ judgment $(\mathrm{J})$. A description of each personality preference is shown below in Table 1.20

An individual with an ENFJ personality type, for example, shows intense compassion, desires harmony in relationships, and enjoys exploring possibilities. Although everyone uses each preference together, only one member of each pair is preferred and regularly used by an individual. ${ }^{32}$ Table 1 shows the current distribution of Meyers Briggs Personality Types across the United States population.

The personality types of physicians vary considerably across the medical profession as seen with MBTI personalities associated with specific medical specialties. ${ }^{27-29}$ A physician with an introverted and sensing personality type would be better suited for the technical work of surgery than for the emotional interactions required in a pediatric or family medicine specialty. Yet the application of previous studies on patient confidence and alignment of physician-patient personalities has been difficult due to lack of physician training and the difficulty in doing studies with these principles in clinical work. In this review, previous studies on patient confidence and alignment of physician-patient personalities will be examined to encourage investigation and application in physician-patient interactions and to help physicians understand the importance of their personality types in effective communication.

\section{THINKING AND FEELING PERSONALITY TYPES ON PATIENT CONFIDENCE}

With the goal to im prove physician-patient communication, understanding patient preferences and physician personality remains vitally important. ${ }^{34}$ In a study performed in the UK, there was a significant 
Table 1. Personality preference summary table to $^{20}$

\begin{tabular}{|c|c|}
\hline \multicolumn{2}{|c|}{ PREFERRED FOCUS OF ATTENTION } \\
\hline Extraversion & Introversion \\
\hline Appears to think aloud & Pauses while giving information \\
\hline Interrupts & Shorter sentences - not run on \\
\hline Louder volume of voice & Quieter voice volume \\
\hline \multicolumn{2}{|c|}{ PREFERRED MODE OF ASSIMILATING INFORMATION } \\
\hline Sensing & Intuition \\
\hline Asks for step by step information or instruction & Asks for current and long-term implications \\
\hline Asks "what" and "how" questions & Asks "why" questions \\
\hline Uses precise descriptions & Talks in general terms \\
\hline \multicolumn{2}{|c|}{ PREFERRED BASIS FOR DECISION MAKING } \\
\hline Thinking & Feeling \\
\hline Appears to be "testing you" or your knowledge & Strives for harmony in interaction \\
\hline Weighs the objective evidence & May talk about what they value \\
\hline Not impressed that others have decided in favour & Asks how others acted/resolved the situation \\
\hline \multicolumn{2}{|c|}{ PREFERRED APPROACH TO MANAGING ONE'S LIFE } \\
\hline Judging & Perceiving \\
\hline Impatient with overly long descriptions or procedures & Conversation may move through many areas \\
\hline The tone is "let's get it done" & $\begin{array}{l}\text { May feel put off by closing a conversation before they're } \\
\text { ready }\end{array}$ \\
\hline $\begin{array}{l}\text { May even decide prematurely and not want to } \\
\text { listen to important considerations }\end{array}$ & $\begin{array}{l}\text { No decision before its time - often at last minute or when } \\
\text { absolutely necessary in their view }\end{array}$ \\
\hline
\end{tabular}

difference in the personality types of physicians and the public, particularly with respect to the sensing/ intuition and thinking/feeling personality types. ${ }^{22}$ These personality differences can have important consequences on clear and effective communication involved in physician-patient interactions. As Gillian Clack explained, "Some individuals prefer being given the straightforward facts in a clear, concise, and practical manner (Sensing with Thinking), others prefer factual information in a caring manner (Sensing with Feeling), others prefer having the overall picture delivered in a personalized manner (Intuition with Feeling), and others prefer the discussion of logical options by a competent practitioner in a manner that respects their intelligence (Intuition with Thinking)."22 In response to this study, the British Medical Journal 


\begin{tabular}{lllll} 
ISTJ & ISFJ & INFJ & INTJ \\
$11-14 \%$ & $9-14 \%$ & $1-3 \%$ & $2-4 \%$ \\
\hline ISTP & ISFP & INFP & INTP \\
$4-6 \%$ & $5-9 \%$ & $4-5 \%$ & $3-5 \%$ \\
\hline ESTP & ESFP & ENFP & ENTP \\
$4-5 \%$ & $4-9 \%$ & $6-8 \%$ & $2-5 \%$ \\
\hline ESTJ & ESFJ & ENFJ & ENTJ \\
$8-12 \%$ & $9-13 \%$ & $2-5 \%$ & $2-5 \%$
\end{tabular}

Figure 1. Estimated Frequencies of the Types in the United States Population.

https://www.capt.org/mbti-assessment/estimatedfrequencies.htm

(BMJ) published an article with two tables, shown in Figures 2 and 3 , summarizing methods physicians can use to identify patient personality preferences and to adjust their interview style based on their initial assessment. ${ }^{35}$ Furthermore, the article cautioned physicians in their approach to assessing a patient's personality arguing that "our behavior can alter when we're stressed. For these reasons it is not only unnecessary to know a patient's preferences in order to conduct a consultation, but it could be misleading. For example, if you knew a patient had preferences for Extraversion, Intuition, and Feeling you might not pick up on the fact that today-possibly because he or she is coming to discuss potentially worrying test results-that patient is contained (Introversion), relatively impersonal (Thinking), and focused on hearing the detailed results of the test (Sensing). What is important is to be able to tune into a patient's current communication style." 35

Thus, ensuring congruent personality types between physicians and patients is crucial for both effective communication and treatment. ${ }^{36}$ This is most clearly seen in physician-interactions based on either a thinking or feeling personality type. In the MBTI, the thinking and feeling personality types describe how

\begin{tabular}{|c|c|}
\hline $\begin{array}{l}\text { Extraversion (E) } \\
\text { - Rapid speech } \\
\text { - Seems to think aloud } \\
\text { - Interrupts } \\
\text { - Louder volume to voice }\end{array}$ & $\begin{array}{l}\text { Introversion (I) } \\
\text { - Pauses in answering or giving information } \\
\text { - Appears to be thinking things through } \\
\text { - Quieter voice volume } \\
\text { - Shorter sentences that don't run on }\end{array}$ \\
\hline $\begin{array}{l}\text { Sensing (\$) } \\
\text { - Asks for step by step information or instructions } \\
\text { - Asks about the present situation } \\
\text { - Asks "what" and "how" questions } \\
\text { - Uses precise descriptions }\end{array}$ & $\begin{array}{l}\text { Intuition (N) } \\
\text { - Asks for the purpose of the action } \\
\text { - Asks for current and long term implications } \\
\text { - Asks "why" questions } \\
\text { - Talks in general terms and possibilities }\end{array}$ \\
\hline $\begin{array}{l}\text { Thinking (T) } \\
\text { - Seems to be testing you or your knowledge } \\
\text { - Weighs up the objective evidence } \\
\text { - Not impressed by what others decide } \\
\text { - Conversations follow a pattern of checking logic, } \\
\text { "If this, then that." }\end{array}$ & $\begin{array}{l}\text { Feeling (F) } \\
\text { - Strives for harmony in the interaction } \\
\text { - May talk about "value" } \\
\text { - Asks how others have acted or resolved a similar } \\
\text { situation } \\
\text { - Matters to them whether others have been taken into } \\
\text { account }\end{array}$ \\
\hline $\begin{array}{l}\text { Judging }(\mathrm{J}) \\
\text { - Impatient with overly long descriptions or procedures } \\
\text { - The tone is "Hurry up ... I want to make this decision." } \\
\text { - Enjoys getting things done }\end{array}$ & $\begin{array}{l}\text { Perceiving (P) } \\
\text { - Seems to want "space" to make a decision } \\
\text { - The tone is, "Let's explore, what are some more factors } \\
\text { to consider?" } \\
\text { - May decide at the last moment } \\
\text { - Enjoys processing }\end{array}$ \\
\hline
\end{tabular}

Figure 2. Behavioral cues of patient personality. ${ }^{35}$ 


\begin{tabular}{|l|l|l|}
\hline Doctors who prefer & When talking to patients who prefer & Could try to \\
\hline Extraversion & Introversion & Use a slower pace and give time for the patient to reflect \\
\hline Introversion & Extraversion & Show more energy and give space for the patient to talk \\
\hline Intuition & Sensing & $\begin{array}{l}\text { Give detailed information in a stepwise fashion, and } \\
\text { practical examples }\end{array}$ \\
\hline Sensing & Intuition & Give the big picture first (see box) \\
\hline Feeling & Thinking & Keep to objective facts and logical information \\
\hline Thinking & Feeling & $\begin{array}{l}\text { Take an interest in the patient as an individual, showing } \\
\text { concern }\end{array}$ \\
\hline Judging & Perceiving & $\begin{array}{l}\text { Provide space for the patient to explore and clarify the } \\
\text { options }\end{array}$ \\
\hline Perceiving & Judging & $\begin{array}{l}\text { Agree an agenda for action including, where possible, } \\
\text { dates by which each item will be dealt with }\end{array}$ \\
\hline
\end{tabular}

Figure 3. Altering communication style based on patient personality preference. ${ }^{35}$ an individual acts with the information given his/her sensing or intuitive personality type. ${ }^{32}$ Individuals with a predisposition for a feeling personality will make judgments predominately on the values of others and themselves, while a thinking individual will act on impersonal facts. ${ }^{32}$ In the clinical setting, physician preference for thinking or feeling in guiding medical decisions and communication significantly impacts patient confidence and treatment. Although the thinking personality may seem to be preferred by both patients and physicians, several studies have demonstrated that the feeling personality type in physicians fosters patient confidence. In a recent survey, surgical patients listed respect of autonomy and verbal communication as most important when developing trust and confidence in a surgeon, followed by technical proficiency. ${ }^{37}$ In the same study, surgical patients had the greatest confidence in surgeons who could clearly explain their medical condition, treatment options, and answered all their concerns. ${ }^{37}$ The authors of the study concluded, "The old perception that being a technically gifted surgeon was sufficient to meet patients' requirements no longer stands. Patients now expect to be treated by a physician with excellent communication skills in addition to his or her technical abilities ... The relationship between the patient and his surgeon has evolved from the traditional paternalizing surgeon-passive patient model to a relationship that is more similar to the interaction between a service provider surgeon and a client-patient." ${ }^{\text {37 }}$

A similar study done in India also found that communication skills, mannerisms, and word of mouth recommendations were most influential in patient confidence and satisfaction. ${ }^{38}$ These results suggest that "Most people are not demanding more information before choosing a doctor because the information available is not what patients wish to know. It seems that a doctor's approachability and manner are easily the most important things that patients look for and that is not available in any printout." ${ }^{38}$ A more recent study in the British Medical Journal showed that patients' confidence depended on patient perceptions on having their concerns and questions taken seriously by their physicians. ${ }^{39}$ However, the same study also showed that the physician's age, gender, and ethnicity influenced patient confidence. ${ }^{39}$ Specifically, the study found that in geriatric patient populations, "A sense of shared decision-making was a stronger determinant of reported confidence and trust among older patients is a new finding. This contrasts with the previous literature which has suggested that older 
patients may prefer a focus on receiving information rather than on active participation." ${ }^{39}$ In summary, these studies suggest that physicians who align their personality types in ways that foster better patient communication can provide better information about diagnosis, prognosis, and concerns with their patients and improve decision making with patients at various ages and demographics.

\section{Conclusions}

The MBTI is a useful tool for understanding and improving communication in all sectors of society. Medicine forces multiple individuals with different personalities to work toward a common goal of providing the best possible patient care in non-ideal circumstances and with limited resources. The most fundamental of these interactions occurs between the patient and the physician. Without the awareness of the contribution personality type plays in physicianpatient interactions, ineffective communication leads to poor management, coordination, and understanding across all medical specialties.

A physician with self-knowledge about personality tendencies can uniquely adapt his/her personality preference to each patient. The pressure for physicians and medical personnel to diagnose and treat more patients with complex medical needs will likely decrease the time and quality of physician-patient interactions. However, the need for improving physician-patient interactions remains crucial for ensuring patient care and safety despite increasing pressures on the medical community. Future medical studies analyzing patient preferences for physician personality in different clinical departments could greatly improve patient-physician interactions.

\section{SUPPLEMENT}

Link to The Meyer's Brigg Personality assessment: http://www.myersbriggs.org/my-mbti-personality-type/ take-the-mbti-instrument/
Article citation: Kopel J. Physician personality and patient confidence. The Southwest Respiratory and Critical Care Chronicles 2018;6(26):30-36

From: Texas Tech University Health Sciences Center School of Medicine, Lubbock, Texas

Submitted: $1 / 16 / 2018$

Accepted: 9/3/2018

Reviewers: Steven Urban MD, Gilbert Berdine MD

Conflicts of interest: none

This work is licensed under a Creative Commons

Attribution-ShareAlike 4.0 International License

\section{REFERENCES}

1. Smith R. All changed, changed utterly. British Medical J 1998;316.

2. Francis V, Korsch BM, Morris MJ. Gaps in doctor patient communication. Pediatrics 1969;280:535-40.

3. Richards T. Chasms in communication. BMJ: British Medical J 1990;301:1407-8.

4. Simpson M, Buckman R, Stewart M, et al. Doctor-patient communication: The Toronto Consensus Statement. British Medical J 1991;303:1385-7.

5. Ha JF, Longnecker N. Doctor-patient communication: A review. The Ochsner J 2010;10:38-43.

6. Calnan M, Sanford E. Public trust in health care: the system or the doctor? Quality Safety in Health Care 2004;13:92-7.

7. Easter DW, Beach WA. Competent patient care is dependent upon attending to empathic opportunities presented during interview sessions. Current Surgery 2004;61:313-8.

8. Axelrod DA, Goold S. Maintaining trust in the surgeon-patient relationship: challenges for the new millennium. Archives Surgery 2000;135:55-61.

9. Urbaniak JR. Presidential address: Physician accountabilitywinning the public trust. American Society for Surgery of the Hand 1993;18A.

10. Dibben M, Davies H. Trustworthy doctors in confidence building systems. Quality Safety in Health Care 2004;13: 88-9.

11. Ommen $\mathrm{O}$, Them $\mathrm{S}$, Pfaff $\mathrm{H}$, et al. The relationship between social support, shared decision-making and patient's trust in doctors: a cross-sectional survey of 2,197 inpatients using the Cologne Patient Questionnaire. International J Public Health 2011;56:319-27. 
12. Britten N, Stevenson FA, Barry CA, et al. Misunderstandings in prescribing decisions in general practice: qualitative study. British Medical J 2000;320:484.

13. Redman CWE, McFarlane $T$, Cottrell $D$, et al. Improving Communication between Doctors and Patients having a Hysterectomy. J Obstetrics Gynaecology 1986;6:275-6.

14. Stewart M, Brown JB, Hammerton J, et al. Improving communication Between doctors and breast cancer patients. Annals Family Medicine 2007;5:1-8.

15. Wright EB, Holcombe C, Salmon P. Doctors' communication of trust, care, and respect in breast cancer: qualitative study. British Medical J 2004;328:864.

16. Clever SL, Jin L, Levinson W, et al. Does Doctor-patient communication affect patient satisfaction with hospital care? Results of an analysis with a novel instrumental variable. Health Services Research 2008;43:1505-19.

17. Williams S, Weinman J, Dale J. Doctor-patient communication and patient satisfaction: a review. Family Practice 1998; 15:480-92.

18. Williams SJ, Calnan M. Key determinants of consumer satisfaction with general Practice. Family Practice 1991; $8: 237-42$.

19. Pollak KI, Alexander SC, Tulsky JA, et al. Physician empathy and listening: associations with patient satisfaction and autonomy. J American Board Family Medicine 2011;24: 665-72.

20. Clack GB, Allen J, Cooper D, et al. Personality differences between doctors and their patients: implications for the teaching of communication skills. Medical Education 2004; 38:177-86.

21. Bonvicini KA, Perlin MJ, Bylund CL, et al. Impact of communication training on physician expression of empathy in patient encounters. Patient Education Counseling 2009; 75:3-10.

22. Clack GB, Allen J, Cooper D, et al. Personality differences between doctors and their patients: implications for the teaching of communication skills. Medical Education 2004; 38:177-86.

23. Duffy FD, Gordon GH, Whelan G, et al. Assessing competence in communication and interpersonal kkills: The Kalamazoo II report. Academic Medicine 2004;79: 495-507.

24. Stewart MA. Effective physician-patient communication and health outcomes: a review. CMAJ 1995;152:1423-33.
25. Ha JF, Anat DS, Longnecker N. Doctor-patient communication: a review. The Ochsner Journal 2010;10:38-43.

26. Capraro RM, Capraro MM. Myers-Briggs type indicator score reliability across studies: A Meta-analytic reliability generalization study. Educational Psychological Measurement 2002;62:590-602.

27. Yang C, Richard G, Durkin M. The association between Myers-Briggs Type Indicator and psychiatry as the specialty choice. International J Medical Education 2016;7:48-51.

28. Borges NJ, Savickas ML. Personality and medical specialty choice: A literature review and integration. J Career Assessment 2002;10:362-80.

29. Stilwell NA, Wallick MM, Thal SE, et al. Myers-Briggs type and medical specialty choice: a new look at an old question. Teaching and Learning in Medicine 2000;12:14-20.

30. Carlson JG. Recent assessments of the Myers-Briggs type indicator. J Personality Assessment 1985;49:356-65.

31. Thompson B, Borrello CM. Construct validity of the MyersBriggs type indicator. Educational Psychological Measurement 1986;46:745-52.

32. McCaulley MH. Looking at Type: The Fundamentals. Gainesville, Florida: Center for Applications of Psychological Type, Inc.; 1997.

33. Cunningham PB. Improved communication and teamwork use of Myers-Briggs type indicator. EMTB '00 Proceedings of the 1st Austin Workshop On Engineering Management In Technology-Base Organizations 2000:31.

34. Little P, Everitt H, Williamson I, et al. Preferences of patients for patient centered approach to cons ultation in primary care: observational study. British Medical J 2001;322: 468-72.

35. Allen J. Doctor-patient communication. British Medical J 2005;330: s36.

36. Krupat E, Bell R, Kravitz RL, et al. When physicians and patients think alike: patient-centered beliefs and their impact on satisfaction and trust. J Family Practice 2001; 50:1057-62.

37. Hamelin ND, Nikolis A, Armano J, et al. Evaluation of factors influencing confidence and trust in the patient-physician relationship: A survey of patient in a hand clinic. Chirurgie de la Main 2012;31:83-90.

38. Singhal I, Singhal A, Singhal S, et al. Factors influencing patients' preference and confidence in a surgeon. Indian $\mathrm{J}$ Basic and Applied Medical Research 2015;4:693-7. 